DOI: $10.7242 / 1998-2097 / 2018.1 .2$

УДК 616.98:578.828HIV

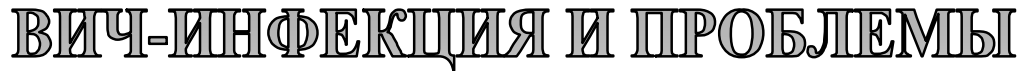

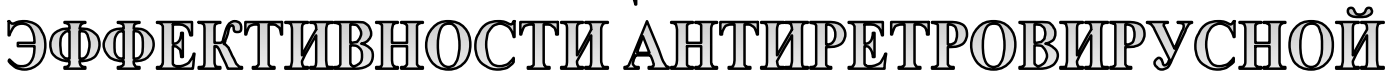

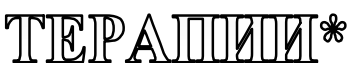

\author{
Е.В. Сайдакова, Институт экологии и генетики микроорганизмов УрО РАН \\ Л.Б. Королевская, Институт экологии и генетики микроорганизмов УрО РАН \\ К.В. Шмагель, Институт экологии и генетики микроорганизмов УрО РАН
}

\begin{abstract}
Представлены общие данные о патогенезе ВИЧ-инфекции. Массивное уничтожение $\mathrm{CD}^{+}$Т-лимфоцитов кишечника в острой фазе заболевания вызывает микробную транслокацию и активацию иммунной системы. При хроническом течении инфекции персистирующая иммунная активация постепенно истощает пул $\mathrm{CD}^{+}$Т-лимфоцитов. Присоединение СПИД-ассоциированных заболеваний на фроне развивающегося иммунодефицита приводит к летальному исходу. Также рассмотрены критерии эффрективности антиретровирусной терапии. Особое внимание уделено феномену дискордантного ответа на лечение.
\end{abstract}

Ключевые слова: ВИЧ-инфекция, патогенез, антиретровирусная терапия, дискордантный ответ.

С начала глобальной эпидемии ВИЧинфекции прошло почти 40 лет. За это время более 76 миллионов человек были заражены вирусом иммунодефицита, свыше 35 миллионов умерли от болезней, сопутствующих СПИД. Ежегодно по всему миру ВИЧ-инфекция уносит жизни примерно одного миллиона человек. При этом заболевание давно вырвалось за пределы отдельных социальных слоев населения, а треть зараженных ВИЧ людей даже не подозревают о том, что инфицированы. В силу незнания они не получают медицинской помощи и, следовательно, не только усугубляют собственное состояние, но и активно способствуют распространению инфекции.

Согласно данным Федерального научно-методического центра по профилактике и борьбе со СПИД, число ВИЧ-поло- жительных людей, проживающих на территории Российской Федерации, достигло почти одного миллиона. В 2017 году показатель пораженности вирусом иммунодефицита жителей России составил 643 человека на 100000 населения. Другими словами по официальным данным, 0,7\% людей, проживающих в России, являются ВИЧ-инфицированными. При этом в 2017 году Пермский край занял шестое место среди регионов России с наивысшими показателями распространенности заболевания. Представленные данные наглядно демонстрируют важность проблемы ВИЧ-инфекции.

Инфицирование ВИЧ влечет за собой постепенное (в течение нескольких лет) разрушение иммунной системы, характеризующееся массивным сокращением числа $\mathrm{CD}^{+}$Т-лимфоцитов, хронической им-

* Работа выполнена в рамках государственного задания; номер госрегистрации темы: 01201353248. 
мунной активацией и системным воспалением. Однако ключевые события, приводящие к необратимым последствиям, развиваются еще в острой фазе ВИЧ-инфекции - первые 3-4 недели с момента заражения - и происходят в желудочно-кишечном тракте. Слизистая оболочка кишечника является уникальным анатомическим и физиологическим барьером, препятствующим проникновению микробов за его пределы (рис. 1). Эффективность защиты обеспечивается присутствием большого количества $\mathrm{CD} 4^{+}$Т-лимфоцитов [14]. Эти клетки являются основными мишенями ВИЧ и независимо от пути передачи инфекции (половой или парентеральный) вирус достаточно быстро оказывается в кишечнике. Здесь в течение короткого промежутка времени ВИЧ уничтожает значительную часть иммунокомпетентных клеток [10]. Нарушение целостности кишечного барьера приводит к выходу потенциально патогенных и условно-патогенных микроорганизмов из просвета кишечника. Неконтролируемое поступление бактерий и их продуктов в кровоток (микробная транслокация) оказывает влияние на иммунокомпетентные клетки, поддерживая состояние хронической иммунной активации. К концу острого периода в слизистой оболочке кишечника вирусом уничтожаются почти все $\mathrm{CD} 4^{+}$Т-клетки. При этом их количество в периферической крови снижается незначительно [16].

Периферическая кровь

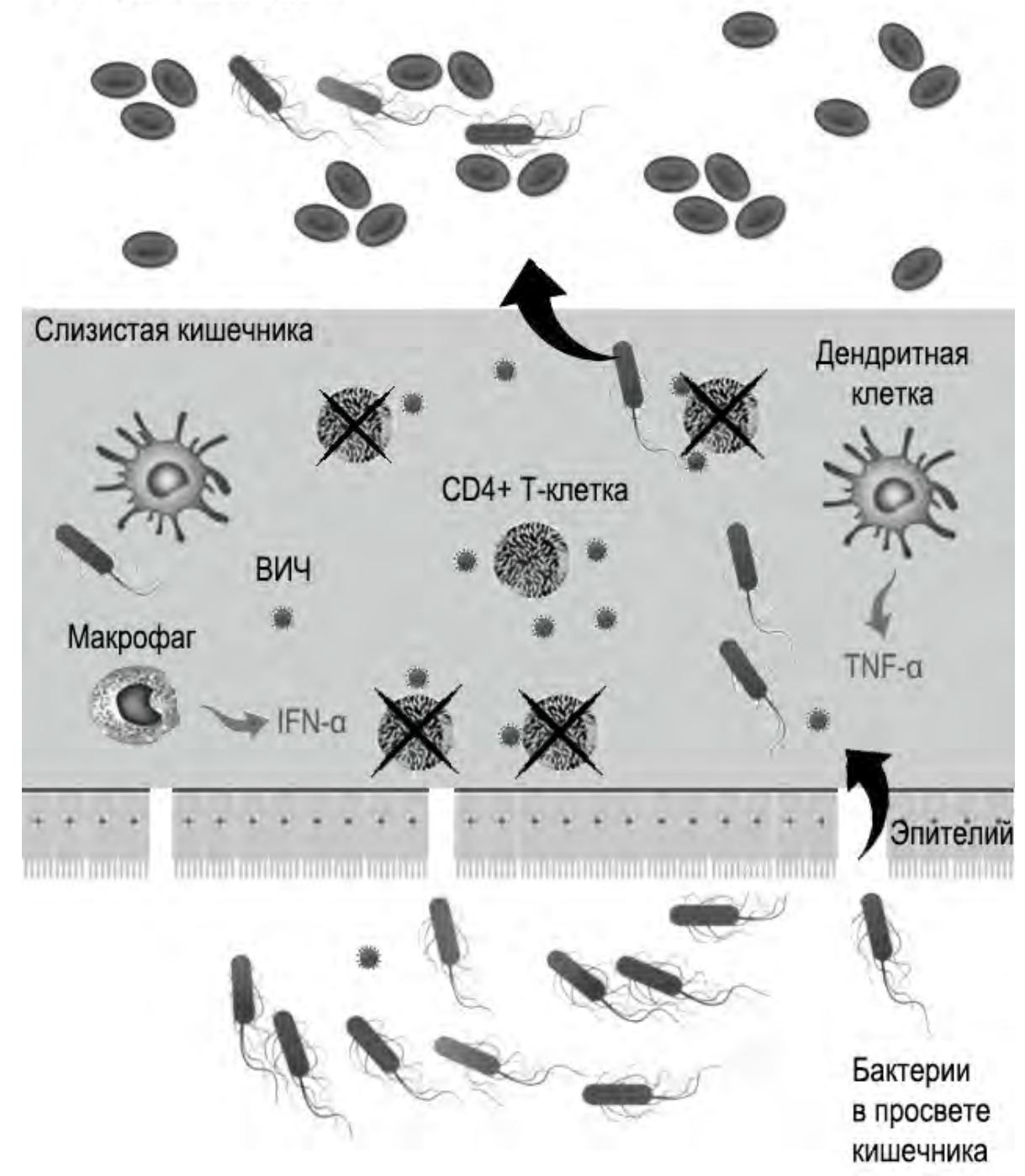

Рис. 1. Повреждение эпителиального барьера желудочно-кишечного тракта при ВИЧ-инфекичи 
В здоровом организме большое количество $\mathrm{CD}^{+}$Т-лимфоцитов, находящихся в слизистой оболочке желудочно-кишечного тракта, поддерживают целостность кишечного барьера. В условиях ВИЧ-инфекции $\mathrm{CD}^{+}{ }^{+}$Т-клетки становятся мишенями для репликации вируса и удаляются из организма. Бактерии и микробные продукты начинают поступать в ткань и периферическую кровь через нарушенный эпителиальный барьер, вызывая провоспалительный ответ иммунокомпетентных клеток.

Важно отметить, что сдвиги, происходящие в иммунной системе в острую фазу ВИЧ-инфекции, не имеют ярких клинических проявлений. Чаще всего симптомы этого периода напоминают банальную вирусную инфекцию с лихорадкой, недомоганием, высыпаниями на коже и слизистой оболочке полости рта, диареей и лимфаденопатией [8]. Как правило, длительность клинических проявлений не превышает четырех недель, а неспецифичность симптомов затрудняет диагностику ВИЧ-инфекции. Кроме того, лабораторное подтверждение инфицирования
ВИЧ в острый период предполагает выявление ранних антигенов вируса, поскольку противовирусные антитела, определение которых обычно проводят для диагностики ВИЧ-инфекции, на этой стадии еще не идентифицируются.

Образование антител к ВИЧ начинается не ранее, чем через две недели после заражения, через 4-6 недель специфические к вирусу антитела обнаруживаются лишь в 60-80\% случаев. Следует отметить важность ранней диагностики ВИЧинфекции не только для своевременного начала лечения больного, но и для предупреждения дальнейшего распространения заболевания. Для острой фазы инфекции характерны высокие темпы репликации ВИЧ: вирусная нагрузка может подниматься до $10^{6}-10^{7}$ копий в 1 мл крови [11]. В этот период ВИЧ-зараженные люди являются основными активными распространителями вируса.

При развитии хронической инфекции уровень периферических $\mathrm{CD}^{+}$T-клеток продолжает постепенно снижаться на протяжении примерно 10 лет (рис. 2). Это происходит на фоне постоянной актива-

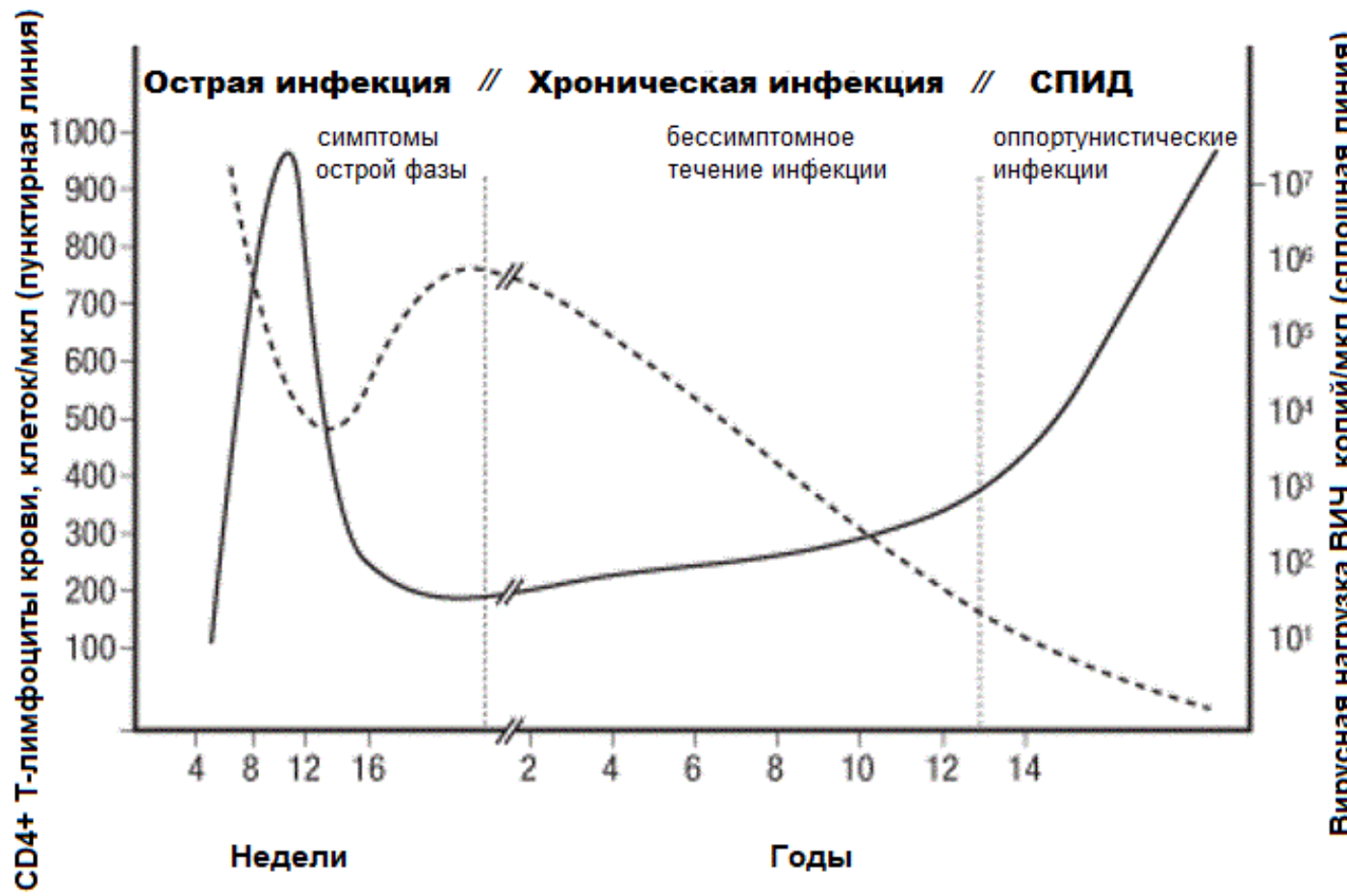

Рис. 2. Кинетика развития ВИЧ-инфекиии. Показаны изменения содержания $C D 4^{+}$T-лимфоцитов (пунктирная линия) и вирусной нагрузки ВИЧ (сплошная линия) в периферической крови 
ции системы иммунитета. Понятие хронической иммунной активации включает в себя целый ряд процессов. Так, у ВИЧ-инфицированных больных увеличивается скорость обновления пула Т-лимфоцитов, что приводит к сокращению времени полужизни Т-клеток. Нарушение механизма гомеостатической пролиферации способствует клональному истощению лимфоцитов и, как следствие, опустошению их пула [6]. Через разрушенный кишечный барьер в кровоток продолжают непрерывно поступать микробные продукты, поддерживающие активированное состояние иммунокомпетентных клеток. Размножение вируса в лимфатических узлах вызывает повреждение лимфоидной ткани и приводит к развитию воспаления. В ответ на воспаление развивается процесс склерозирования. Заполнение лимфатических узлов соединительной тканью нарушает нормальное микроокружение, необходимое для поддержания жизнеспособности Т-лимфоцитов. Дополнительным источником воспаления являются сопутствующие заболевания (цитомегаловирусная инфекция, герпес, и т.д.). Кроме того, результатом активации иммунитета является экспансия Т-клеточных субпопуляций, создающая новые мишени и субстрат для репликации вируса. В итоге именно уровень активации иммунной системы определяет скорость снижения количества $\mathrm{CD}^{+}$ T-клеток и прогрессирования заболевания.

Когда количество периферических $\mathrm{CD} 4^{+}$Т-лимфоцитов падает ниже определенного уровня (200 клеток/мкл), ВИЧинфекция переходит в третью, завершающую фазу - СПИД. По мере того, как разрушается иммунная система, больные становятся все больше подвержены таким заболеваниям как туберкулез, грибковые, вирусные и паразитарные инфекции, опухоли [9]. Смерть наступает в результате неспособности организма справиться с сопутствующими заболеваниями.

Попытки лечения зараженных ВИЧ больных сопровождают всю историю изучения ВИЧ-инфекции. Более 20 лет назад с началом использования антирет- ровирусных препаратов, казалось, успех был гарантирован. Назначение антиретровирусной терапии (АРТ) сопровождалось снижением уровня вирусной нагрузки ВИЧ в крови и увеличением числа периферических $\mathrm{CD} 4^{+}$Т-лимфоцитов. Вместе с тем необходимо отметить, что АРТ не приводит к полному удалению ВИЧ из организма. Отмена препаратов сопровождается реактивацией вируса и увеличением его концентрации в плазме крови больных. Наличие резервуаров репликации ВИЧ может быть одним из факторов, поддерживающих активацию иммунитета у ВИЧ-инфицированных больных, получающих АРТ.

Следует также отметить, что позитивным моментом применения специфической терапии является очевидное снижение частоты развития СПИД-ассоциированных заболеваний и увеличение продолжительности жизни пациентов. Таким образом, ВИЧ-инфекция как хроническое заболевание, хотя и неизлечимо, но может успешно контролироваться пожизненным приемом антиретровирусных препаратов.

Эффективность АРТ оценивается по двум критериям. Во-первых, так как основной целью терапии является подавление репликации ВИЧ, успешность лечения устанавливают по снижению концентрации вируса в крови. Вирусная нагрузка менее 50 копий в 1 мл крови - показатель эффективности антиретровирусных препаратов. В то же время многочисленные исследования продемонстрировали, что концентрация ВИЧ не является ключевым фактором, определяющим прогрессирование заболевания [13]. Скорость развития СПИД, в первую очередь, обусловлена количеством $\mathrm{CD} 4^{+}$T-лимфоцитов. В связи с этим вторым и более важным критерием оценки эффективности лечения является увеличение числа периферических $\mathrm{CD}^{+}$T-лимфоцитов в крови [7].

К сожалению, результат терапии не всегда удовлетворителен. Приблизительно у $30 \%$ ВИЧ-инфицированных пациен- 
тов, получающих лечение, развивается так называемый дискордантный ответ. Он представляет собой несоответствие между эффективностью подавления вирусной нагрузки и скоростью прироста количества периферических $\mathrm{CD}^{+}$T-клеток. Существует два варианта дискордантного ответа на АРТ. Первый характеризуется увеличением числа $\mathrm{CD}^{+}{ }^{+}$Т-лимфоцитов при частичном подавлении вирусной нагрузки [13]. Таких пациентов называют вирусологическими неответчиками. Феномен можно частично объяснить мутациями ВИЧ, делающими вирус менее восприимчивым к антиретровирусным препаратам [17].

Второй вариант дискордантного ответа на лечение обнаружен среди ВИЧ-инфицированных больных, у которых, несмотря на эффективное подавление вирусной нагрузки на фоне АРТ, не происходит прирост числа $\mathrm{CD} 4^{+} \mathrm{T}$-лимфоцитов [5]. В литературе для таких пациентов был введен термин «иммунологические неответчики». Ввиду сохраняющегося иммунодефицитного состояния ВИЧ-инфицированные иммунологические неответчики, в отличие от пациентов со стандартным ответом иммунной системы на терапию, подвержены большему риску развития СПИД-ассоциированных и СПИД-неассоциированных заболеваний [12]. Причины развития иммунологического неответа на лечение остаются малопонятными.

К настоящему времени выявлены несколько факторов риска формирования дискордантного ответа на АРТ. Убедительно показано, что назначение антиретровирусных препаратов больным с выраженным иммунодефицитом часто не приводит к эффективному приросту числа $\mathrm{CD} 4^{+}$Т-клеток [4]. Более раннее начало лечения ассоциировано с благоприятным прогнозом восстановления численности клеток.

Другим фактором, влияющим на результативность терапии при ВИЧ-инфекции, является возраст больного [4]. Чем старше ВИЧ-инфицированный пациент, тем медленнее его организм увеличивает число $\mathrm{CD}^{+}$T-клеток при проведении терапии. Эффект возраста на восстановление иммунитета при АРТ обусловлен изменением в работе вилочковой железы пациентов, которая под действием возрастной инволюции снижает продукцию наивных Т-клеток [2]. В случае, если вилочковая железа сохраняет свою функциональную активность, поступающие на периферию новые наивные Т-клетки пополняют пул $\mathrm{CD}^{+}$Т-лимфоцитов, способствуя реконструкции иммунной системы.

Третьим важным фактором риска развития дискордантного ответа на лечение является коинфицирование вирусом гепатита С (ВГС) [15]. Так, после назначения APT темпы прироста числа $\mathrm{CD}^{+}$T-клеток у ВИЧ/ВГС-коинфицированных индивидуумов были снижены в 7 раз по сравнению с аналогичным показателем ВИЧ моноинфицированных пациентов [15]. По мнению авторов, это было связано с уровнем репликации ВГС.

Следует также отметить, что ВИЧ отягощает течение ВГС-инфекции, ускоряя фиброзирование печеночной ткани, ведущее к циррозу печени [3]. Эти данные особенно актуальны в свете широкой распространенности ВИЧ/ВГС-коинфекции: в России среди ВИЧ-положительных больных более $60 \%$ коинфицированы ВГС [1].

Таким образом, неэффективность восстановления иммунной системы на фоне антиретровирусной терапии на сегодняшний день является одной из наиболее острых проблем иммунологии ВИЧ-инфекции. Постоянное расширение назначения АРТ ВИЧ-инфицированным пациентам, с одной стороны, и связанное с ним неуклонное повышение среднего возраста ВИЧ-положительных больных - с другой, ведет к увеличению как относительной, так и абсолютной численности иммунологических неответчиков.

Патогенетические основы развития феномена неответа остаются малопонятными. Важно подчеркнуть, что непонимание биологических законов формирования 
слабой способности $\mathrm{CD}^{+}$Т-лимфоцитов к регенерации при подавленной вирусной нагрузке не позволяет приступить к разработке эффективных терапевтических мероприятий и приводит к значительным людским и финансовым потерям.

Выяснение механизмов развития дискордантного ответа $\mathrm{CD}^{+}$T-клеток на лечение ВИЧ-инфекции является предметом исследования, проводимого в Институте экологии и генетики микроорганизмов УрО РАН. В настоящее время совместно с американскими коллегами из Западного резервного университета Кейза (Кливленд, штат Огайо), возглавляемыми Майклом Ледерманом, мы проверяем гипотезу об ослаблении у иммунологических неответчиков контроля восстановления утраченных $\mathrm{CD}^{+}$T-лимфоцитов со стороны регуляторных клеток. Нам уже удалось получить важные, на наш взгляд, данные. Действительно, численность регуляторных клеток при формировании неответа оказалась сниженной. Также удалось показать, что $\mathrm{CD} 4^{+}$T-клетки памяти у таких пациентов на фоне ослабления тормозных механизмов активно и непрерывно делятся, пытаясь ликвидировать иммунный дефицит. Однако многократные циклы деления лимфоцитов приводят к истощению митохондрий - «энергетических станций», обеспечивающих любую работу клетки. Выяснилось, что многие потомки пролиферирующих лимфоцитов не способны совершить более одного акта деления: этот процесс мобилизует все их небольшие резервы и они погибают. Теперь необходимо искать выход из этой ситуации, чему мы планируем посвятить дальнейшие исследования.

\section{Библиографический список}

1. Шмагель Н.Г., Шмагель К.В., Черешнев В.А. Клинические аспекты неэффективности высокоактивной антиретровирусной терапии // Инфекционные болезни. - 2011. - Т. 9(1). - С. 5-10.

2. Benveniste $O$. [et al.] Mechanisms involved in the low-level regeneration of CD4+ cells in HIV-1-infected patients receiving highly active antiretroviral therapy who have prolonged undetectable plasma viral loads // J. Infect. Dis. - 2005. - Vol. 191(10). - P. 1670-1679.

3. Deng L.P. [et al.] Impact of human immunodeficiency virus infection on the course of hepatitis $\mathrm{C}$ virus infection: a meta-analysis // World J. Gastroenterol. - 2009. - Vol. 15(8). - P. 996-1003.

4. Florence E. [et al.] Factors associated with a reduced CD4 lymphocyte count response to HAART despite full viral suppression in the EuroSIDA study // HIV Med. - 2003. - Vol. 4(3). - P. 255-262.

5. Grabar S. [et al.] Clinical outcome of patients with HIV-1 infection according to immunologic and virologic response after 6 months of highly active antiretroviral therapy // Ann. Intern. Med. - 2000. Vol. 133(6). - P. 401-410.

6. Grossman Z. [et al.] CD4+ T-cell depletion in HIV infection: are we closer to understanding the cause? // Nat. Med. - 2002. - Vol. 8(4). - P. 319-323.

7. Hammer S.M. [et al.] A controlled trial of two nucleoside analogues plus indinavir in persons with human immunodeficiency virus infection and CD4 cell counts of 200 per cubic millimeter or less. AIDS Clinical Trials Group 320 Study Team // N. Engl. J. Med. - 1997. - Vol. 337(11). - P. 725-733.

8. Hecht F.M. [et al.] Use of laboratory tests and clinical symptoms for identification of primary HIV infection // AIDS. - 2002. - Vol. 16(8). - P. 1119-1129.

9. Hoffman C., Rockstroh J., Kamps S. HIV Medicine. - Flying Publisher, 2006. - 826 p.

10. Kewenig $S$. [et al.] Rapid mucosal CD4(+) T-cell depletion and enteropathy in simian immunodeficiency virus-infected rhesus macaques // Gastroenterology. - 1999. - Vol. 116(5). - P. 1115-1123.

11. Koup R.A. [et al.] Temporal association of cellular immune responses with the initial control of viremia in primary human immunodeficiency virus type 1 syndrome // J. Virol. - 1994. - Vol. 68(7). - P. 4650-4655.

12. Lapadula $G$. [et al.] Risk of clinical progression among patients with immunological nonresponse despite virological suppression after combination antiretroviral treatment // AIDS. - 2013. - Vol. 27(5). P. 769-779.

13. Mezzaroma I. [et al.] Clinical and immunologic response without decrease in virus load in patients with AIDS after 24 months of highly active antiretroviral therapy // Clin. Infect. Dis. - 1999. - Vol. 29(6). P. 1423-1430.

14. Mowat A.M., Viney J.L. The anatomical basis of intestinal immunity // Immunol. Rev. - 1997. Vol. 156. - P. 145-166.

15. Potter $M$. [et al.] Impact of hepatitis $\mathrm{C}$ viral replication on CD4+ T-lymphocyte progression in HIV-HCV coinfection before and after antiretroviral therapy // AIDS. - 2010. - Vol. 24(12). - P. 1857-1865. 
16. Smit-McBride Z. [et al.] Gastrointestinal T lymphocytes retain high potential for cytokine responses but have severe $\mathrm{CD} 4(+) \mathrm{T}$-cell depletion at all stages of simian immunodeficiency virus infection compared to peripheral lymphocytes // J. Virol. - 1998. - Vol. 72(8). - P. 6646-6656.

17. Taylor-Castillo L. [et al.] Study of antiretroviral mutants in HIV patients with treatment failures and the effect of risk factors in the virological failures // Rev. Inst. Med. Trop. Sao Paulo. - 2005. - Vol. 47(6). P. 327-331.

\title{
HIV-INFECTION AND PROBLEMS OF ANTIRETROVIRAL THERAPY EFFECTIVENESS
}

\author{
E.V. Saidakova, L.B. Korolevskaya, K.V. Shmagel \\ Institute of Ecology and Genetics of Microorganisms UB RAS
}

General data on HIV-infection pathogenesis are presented. Massive destruction of $\mathrm{CD}^{+}$ T-lymphocytes in the intestine during the acute phase of the disease causes microbial translocation and immune system activation. With a chronic course of infection, persistent immune activation gradually depletes the $\mathrm{CD} 4^{+} \mathrm{T}$-lymphocyte pool. Together with AIDS-associated diseases it leads to a fatal outcome against the backdrop of developing immunodeficiency. Efficiency criteria of antiretroviral therapy are also considered. Particular attention is paid to the phenomenon of discordant response to the treatment.

Keywords: HIV-infection, pathogenesis, antiretroviral therapy, discordant response.

\section{Сведения об авторах}

Сайдакова Евгения Владимировна, кандидат биологических наук, младший научный сотрудник лаборатории экологической иммунологии, Институт экологии и генетики микроорганизмов УрО РАН - филиал Пермского федерального исследовательского центра УрО РАН (ИЭГМ УрО РАН), 614081, г. Пермь, ул. Голева, 13; e-mail: radimira@list.ru

Королевская Лариса Борисовна, кандидат медицинских наук, научный сотрудник лаборатории экологической иммунологии, ИЭГМ УрО РАН; e-mail: bioqueen@mail.ru

Шмагель Константин Владимирович, доктор медицинских наук, заведующий лабораторией экологической иммунологии, ИЭГМ УрО РАН; e-mail: shmagel@iegm.ru 